\title{
Distresse moral de médicos relacionado à incerteza moral frente às diretivas
}

\section{antecipadas de vontade}

\author{
Physician's moral-uncertainty-distress related to advance directives
}

Sufrimiento moral de médicos relacionada con la incertidumbre moral en las directivas anticipadas de voluntad

\begin{abstract}
Resumo
Moral-uncertainty-distress (MUD) é o distresse moral relacionado ao conflito sobre qual melhor decisão em situações moralmente complexas. Propomos identificar a relação entre percepção do médico sobre as Diretivas Antecipadas de Vontade (DAV) e MUD, assim como o impacto na tomada de decisão. Neste estudo qualitativo, realizou-se entrevistas semiestruturadas com oito médicos de um hospital em Curitiba-PR tendo por base uma DAV verídica e, posteriormente, submetidas ao método de análise de conteúdo por categorização de Bardin. A primeira categoria identificada, DAV como elementos de conflito moral, revelou atitudes paternalistas por parte dos entrevistados, assim como insegurança por incertezas prognósticas, questionamento das DAV considerando motivações prévias do paciente e pouco conhecimento sobre as DAV. O reconhecimento das DAV como instrumentos de exercício da autonomia do paciente constituiu a segunda categoria encontrada. Apesar da identificação das DAV como ferramentas de autonomia, outros aspectos se mostraram moralmente desafiadores para os médicos entrevistados, sendo potencial fonte de MUD e impactando a tomada de decisão.
\end{abstract}

Palavras-chave: Diretivas antecipadas; Autonomia pessoal; Bioética; Médicos.

\begin{abstract}
Moral-uncertainty-distress (MUD) is defined as moral distress related to conflict about best course of action in morally complex situations. We aim to correlate physician's perception about advance directives (AD) with MUD, identifying the impact it promotes on clinical decision making. In this a qualitative study, were semi-structured interviews with eight physicians of a hospital in Curitiba-PR, then submitted to analysis content technique by Bardin. The first category identified, $\mathrm{AD}$ as a morally challenging element, revealed paternalistic attitudes by some participants, as also insecurities in uncertain prognoses, uncertainty about patient motivations to write the document and little previous knowledge about $\mathrm{AD}$ by them. The recognition of $\mathrm{AD}$ as instruments that exercises patient's autonomy was the second category. Although AD were comprehended as instruments of autonomy, other elements were morally challenging, which can be a source of MUD to physician and impact decision making process.
\end{abstract}

Keywords: Advance directives; Personal autonomy; Bioethics; Physicians. 


\begin{abstract}
Resumen
Moral-uncertainty-distress (MUD) es el sufrimiento moral relacionado con conflicto sobre qué decisión es mejor en situaciones moralmente complejas. Proponemos identificar la relación entre la percepción del médico de las Directivas Anticipadas de Voluntad (DAV) y MUD, así como el impacto en la toma de decisiones. En este estudio cualitativo, se realizaron entrevistas semiestructuradas con ocho médicos de un hospital en Curitiba-PR, sometidas al método de análisis de contenido por categorización de Bardin. La primera categoría identificada, DAV como elementos de conflicto moral, reveló actitudes paternalistas de algunos participantes, así como inseguridad debido a incertidumbres pronósticas, duda de las DAV considerando las motivaciones previas del paciente y poco conocimiento sobre las DAV por ellos. El reconocimiento de las DAV como instrumentos para ejercer la autonomía del paciente fue la segunda categoría. Aunque las DAV se han identificado como herramientas para la autonomía, otros aspectos han resultado ser un desafío moral, siendo una fuente potencial de MUD e impactando la toma de decisiones.
\end{abstract}

Palabras clave: Directivas anticipadas; Autonomía personal; Bioética; Médicos.

\title{
1. Introdução
}

O Moral-uncertainty-distress (MUD) é definido por Fourie (2018) como o distresse moral relacionado à incerteza ou conflito moral do profissional sobre qual o melhor curso de ação a ser seguido. Portanto, o MUD se difere do distresse moral relacionado ao constrangimento moral ou, como sugerido por Fourie (2018), moral constraint distress, cuja definição se aproxima do conceito de distresse moral originalmente proposto em 1984 por Jameton (Jameton, 2013). Nesta, o distresse moral relaciona-se principalmente à limitação de ação do profissional de enfermagem, por constrangimentos institucionais, a fazer o que considera moralmente correto, culminando em sentimentos de angústia e sofrimento, que podem ou não se tornarem residuais. Tal definição limita o distresse moral a dois aspectos principais e mutuamente excludentes: a presença da restrição por colega de trabalho e/ou instituição e a ausência de conflito moral - o profissional sabe qual a decisão moralmente correta, no entanto está impedido de tomá-la (Campbell, Ulrich, \& Grady, 2016; Fourie, 2015; Jameton, 2017). Sob o modelo proposto por Jameton, estudos têm identificado a presença de distresse moral nos mais variados contextos de saúde, incluindo no cenário dos Cuidados Paliativos (Corradi-Perini, Beltrão, \& Ribeiro, 2020). Diversos autores têm criticado o modelo de Jameton por este não contemplar situações moralmente desafiadoras vivenciadas pelo profissional de saúde, que não necessariamente passam por constrangimento institucional, mas podem igualmente culminar em sentimentos negativos e interferir desfavoravelmente na atuação do profissional (Campbell et al., 2016; Fourie, 2015; Morley, Bradbury-Jones, \& Ives, 2019).

Fourie (2018), portanto, argumenta que o distresse moral deve ser entendido como a resposta psicológica do profissional de saúde a situações desafiadoras do ponto de vista moral, a exemplo do constrangimento de ação e/ou da incerteza moral, e qualquer profissional de saúde estaria suscetível a sofrê-lo, incluindo o profissional médico. Nesse sentido, o distresse moral se manifesta na forma de sentimento de culpa por parte do profissional, causando impacto no processo de tomada de decisão moral e/ou clínica em situações moralmente complexas (Campbell et al., 2016; Fourie, 2015; Mccarthy \& Deady, 2008). No entanto, os instrumentos validados e utilizados para mensuração do distresse moral, seja no Brasil ou no exterior, têm por base de construção o distresse relacionado ao constrangimento moral de Jameton, ignorando o distresse moral relacionado ao conflito ou incerteza moral (Barlem, Lunardi, Lunardi, Dalmolin, \& Tomaschewski, 2012; Bernardi, Villagran, Lanes, Schutz, \& Dalmolin, 2020; Corley, Elswick, Gorman, \& Clor, 2001; Greco et al., 2020; Hamric, Borchers, \& Epstein, 2012; Lamiani, Setti, Barlascini, Vegni, \& Argentero, 2017; Ramos et al., 2017; Savel \& Munro, 2015). Dessa forma, carece na literatura trabalhos que avaliem o distresse moral sob a perspectiva do conflito ou incerteza moral, principalmente no profissional médico.

No contexto das situações moralmente complexas e incertas, incluem-se as Diretivas Antecipadas de Vontade (DAV). No Brasil, as DAV se desdobram nos documentos 'testamento vital' e 'mandato duradouro, sendo redigida apenas em caso de indivíduo em pleno gozo de sua capacidade mental; capaz, portanto, de exercer sua autonomia. O testamento vital contempla 
as condições e intervenções às quais o paciente desejaria ou não se submeter, em caso de uma doença ou condição clínica não reversível, estando o mesmo incapaz de expressar suas vontades (Dadalto, 2013; Dadalto, Tupinambás, \& Greco, 2013; Nunes \& Anjos, 2014). Nas mesmas condições, o mandato duradouro contempla a nomeação de uma pessoa de confiança do paciente para que esta tome as decisões acerca dos cuidados em saúde (Dadalto, 2013; Dadalto et al., 2013; Nunes \& Anjos, 2014). Apesar de terem por escopo atuar como instrumentos para auxiliar o paciente a exercer sua autonomia e o profissional de saúde no processo de tomada de decisão (Rietjens et al., 2017), o documento levanta questionamentos a respeito do formato de construção e registro, complexidade e incerteza das mais diversas situações clínicas, assim como o fato de que as determinações do paciente presentes nas DAV refletem aspectos culturais e de valores do mesmo, pautando-se em uma situação que pode ser ainda hipotética ao indivíduo. Estes elementos podem tornar-se fonte de insegurança para o profissional médico ao acolher as DAV no momento de decisão clínica (Chehuen Neto et al., 2015; Nunes \& Anjos, 2014).

Do ponto de vista de normatização das DAV para o profissional médico, o Conselho Federal de Medicina (CFM) o faz em sua Resolução número 1.995 de agosto de 2012 que, por sua vez, pode ser interpretada como tendo valor legal visto sua consonância com a Constituição da República Federativa do Brasil (Bussinger \& Barcellos, 2013). A Resolução do CFM define as DAV, em seu artigo $1^{\circ}$, como "conjunto de desejos, prévia e expressamente manifestados pelo paciente, sobre cuidados e tratamentos que quer, ou não, receber no momento em que estiver incapacitado de expressar, livre e autonomamente, sua vontade" (Conselho Federal de Medicina, 2012). Dessa forma, o CFM toma por DAV o conceito de testamento vital, no entanto compreende a existência da possibilidade de designação de um procurador em saúde como parte do documento, como expresso no parágrafo 1 do artigo $1^{\circ}$ (Conselho Federal de Medicina, 2012): "caso o paciente tenha designado um representante para tal fim, suas informações serão levadas em consideração pelo médico" .

$\mathrm{O}$ registro pode ser realizado formalmente em cartório ou mesmo no próprio prontuário médico, porém não há padronização quanto á redação do documento ou legislação específica até o momento, o que nos difere de diversos outros países que possuem melhor regulamentação das DAV. No entanto, apenas a presença de leis relacionadas não soluciona os conflitos morais suscitados pelo documento por parte do profissional médico, o que se observa em países onde a DAV já dispões de legislação específica (Horn, 2014). Dessa forma, os conflitos morais potencialmente suscitados por uma DAV extrapolam o âmbito da legalidade do documento. Mesmo em países como os Estados Unidos da América, com quase 30 anos de história desde a sua proposição, as DAV têm enfrentado diversas críticas quanto a aspectos chaves de sua composição, principalmente relacionados à possível pouca acurácia do que está sendo previsto para o futuro e ao baixo conhecimento do indivíduo sobre o que está sendo decidido do ponto de vista técnico (Levi \& Green, 2010). Assim, possivelmente, a presença de legislação e/ou padronização do documento não exime os profissionais de saúde de incertezas em relação ao mesmo, o que pode levar ao MUD.

Reconhecendo-se as limitações enfrentadas pelas DAV e o papel do médico na tomada de decisão, seria uma DAV previamente construída pelo paciente fonte de distresse moral relacionado a incertezas morais (MUD) no momento de tomada de decisão para o médico? Nossa hipótese é de que o MUD está de fato presente nessas situações, por meio do desconforto moral no momento de tomada de decisão. Para responder a essa pergunta, e por se tratar de um estudo conduzido com profissionais médicos, optamos, no presente estudo, por adotar a definição de DAV proposta pelo CFM, na resolução que versa sobre o tema. Ao investigar essa questão, é possível fornecer subsídios que auxiliem na tomada de decisão médica a fim de atenuar o potencial MUD, bem como amenizar os riscos da obstinação terapêutica e do desrespeito à autonomia do indivíduo.

Para responder a hipótese aventada, é necessário compreender quais as percepções dos médicos frente às DAV, assim como as questões morais e legais suscitadas pelo documento. Portanto, o presente estudo pretende analisar a percepção do profissional médico sobre as DAV correlacionando-a à presença ou ausência de MUD, na definição de distresse moral relacionado à incerteza moral proposta por Fourie (2015). Especificamente, propõe também identificar o impacto que as DAV 
promovem na tomada decisão médica, descrevendo as motivações morais que determinam a conduta do médico frente a estas.

\section{Metodologia}

Trata-se de uma pesquisa qualitativa e de caráter exploratório. Os dados foram coletados por meio de entrevistas, estas analisadas pelo método de análise de conteúdo por categorização proposto por Bardin (2011). A fim de conferir maior rigor metodológico ao estudo, empregou-se o checklist Consolidated criteria for reporting qualitative research (COREQ) (Tong, Sainsbury, \& Craig, 2007).

Foram selecionados para a entrevista, em amostragem por conveniência, oito médicos que na ocasião trabalhavam em um hospital filantrópico localizado na cidade de Curitiba - PR. Foi considerado critério de inclusão médicos hospitalistas, ou seja, que realizavam assistência direta a pacientes admitidos em enfermaria, Unidade de Terapia Intensiva (UTI) e/ou Unidade de Emergência. A amostragem por conveniência se deu por ser este o hospital onde foi atendido o paciente cuja DAV é apresentada neste estudo.

A entrevista foi conduzida pela autora principal deste estudo, seguindo roteiro semiestruturado composto de duas etapas: (i) dados sociodemográficos dos participantes como gênero, idade, ano de graduação e local de atuação na instituição; (ii) questões sobre as DAV, incluindo experiências prévias e apresentação de vinheta clínica que envolvia situação de tomada de decisão relacionada às DAV. Nesta segunda etapa, apresentou-se ao médico a DAV verídica de um paciente admitido naquele hospital no ano anterior. Após apresentação do documento, seguiam-se as seguintes perguntas: "como o (a) $\operatorname{Sr}($ a) $\operatorname{se}$ posicionaria como médico(a) deste paciente em uma situação de emergência?" e, em seguida, "como o (a) $\operatorname{Sr}(a)$ se sente frente a essa Diretiva Antecipada de Vontade do paciente?".

A DAV utilizada pertencia a um paciente do sexo masculino, confeccionada e registrada em 1994, no entanto apresentada pelo próprio paciente à equipe de saúde do hospital no ano de 2018, sem modificações em seu texto. Segue a transcrição literal e completa do documento:

"Em caso de problemas cardíacos graves em meu corpo, não quero ponte de safena nem transplante cardíaco. Também não quero ter minha vida física prolongada artificialmente através do uso de aparelhos. Quero partir consciente para o outro lado da vida. Estou consciente do que estou pedindo. Minha esposa está de pleno acordo com o que ora escrevo. Respeitem minha vontade, assim como gostariam que respeitassem a sua. Agradeço a compreensão."

Os participantes do estudo foram identificados com código alfanumérico (M1 a M8) - 'M' em referência à 'médico (a)' e a sequência numérica relacionada à ordem cronológica das entrevistas. O conteúdo das entrevistas foi integralmente transcrito e submetido a correções gramaticais simples para facilitar a leitura, tendo a cautela de não se alterar o conteúdo presente no discurso dos participantes. O método de análise de conteúdo por categorização de Bardin foi adotado neste estudo por permitir a análise do conteúdo das comunicações por meio de técnicas e procedimentos sistemáticos, objetivando a descrição do conteúdo das mensagens de forma que se possa realizar sua interpretação com o rigor metodológico necessário. O processo é dividido em três etapas: pré-análise, exploração do material - em que se dá o processo de categorização, com a construção das categorias e seus respectivos núcleos de sentido e unidades de registro - e tratamento dos resultados, que comtemplam inferência e interpretação dos dados obtidos conforme a hipótese levantada no estudo (Bardin, 2011).

O estudo foi submetido e aprovado por Comitê de Ética em Pesquisa da Pontifícia Universidade Católica do Paraná, CAAE $n^{\circ}$ 03223318.5.0000.0020, sendo o Termo de Consentimento Livre e Esclarecido formalizado junto à cada participante previamente à entrevista. A DAV utilizada foi obtida com a permissão escrita do paciente e teve sua identificação 
adequadamente omitida a fim de proteção deste.

\section{Resultados}

Do total de participantes incluídos no estudo, seis eram médicos hospitalistas, um atuava em UTI/Unidade de Emergência e um atuava em ambos os cenários - UTI/Unidade de Emergência e enfermaria. Dois participantes eram do sexo feminino e seis do sexo masculino. A idade média dos participantes foi de 43 anos, com intervalo interquartil de 36-48 anos. A média de tempo de atuação desde a graduação foi de 18 anos, com intervalo interquartil de 10-24 anos.

Como resultado do processo de análise de conteúdo por categorização de Bardin, duas categorias emergiram do discurso dos participantes: DAV como elemento de conflito moral $(n=6)$ e reconhecimento das DAV como instrumentos de exercício de autonomia do paciente $(n=4)$. Explorando os elementos que justificassem a primeira categoria levantada, identificamos os núcleos de sentido: atitude paternalista na tomada de decisão $(n=2)$, inseguranças relacionadas às DAV na incerteza prognóstica $(\mathrm{n}=2)$; incerteza sobre a validade das DAV considerando valores e motivações do paciente ao escrever o documento $(n=4)$ e pouco conhecimento prévio a respeito das DAV levando ao desconforto do médico $(n=2)$. Seguindo o mesmo processo, a segunda categoria se subdividiu nos núcleos de sentido autonomia como princípio prima facie $(\mathrm{n}=1) \mathrm{e}$ autonomia compartilhada $(\mathrm{n}=3)$.

Na Tabela 1 encontram-se descritos integralmente os núcleos de registro referentes à cada categoria/núcleo de sentido oriundos do processo de categorização. 
Tabela 1: Categorização do conteúdo das entrevistas segundo o método de análise de conteúdo por categorização de Bardin (2011).

\begin{tabular}{|c|c|c|}
\hline Categorias & $\begin{array}{l}\text { Núcleos de } \\
\text { sentido }\end{array}$ & Unidades de Registro \\
\hline \multirow[t]{11}{*}{$\begin{array}{l}\text { DAV como } \\
\text { elementos de } \\
\text { conflito moral }\end{array}$} & \multirow{2}{*}{$\begin{array}{l}\text { Postura } \\
\text { paternalista na } \\
\text { tomada de } \\
\text { decisão }\end{array}$} & $\begin{array}{l}\text { M5: “(...) desperta o sentimento de insegurança, assim, acho interessante partir do } \\
\text { paciente de iniciativa, mas desperta uma certa insegurança, porque é uma pessoa leiga } \\
\text { falando de coisas técnicas (...)." }\end{array}$ \\
\hline & & $\begin{array}{l}\text { M6: "(...) muitas famílias querem uma coisa e a gente como profissional talvez tenha } \\
\text { uma visão mais apurada do que aquela coisa vai trazer."; “(...) Muitas dessas decisões, } \\
\text { num momento de compartilhar, muitas vezes você tem que entregar algo até que você } \\
\text { fique um pouco desconfortável mas às vezes você tem que entregar algo, e muitas vezes } \\
\text { você também consegue trazer o paciente e a família pra aquela visão e você acaba } \\
\text { trazendo eles pro que é justo(...)" }\end{array}$ \\
\hline & \multirow{2}{*}{$\begin{array}{l}\text { Inseguranças } \\
\text { relacionadas às } \\
\text { DAV na } \\
\text { incerteza } \\
\text { prognóstica }\end{array}$} & $\begin{array}{l}\text { M5: “(...) o documento por si só me influenciaria na hora da emergência, se essa seria a } \\
\text { única coisa que ia contar. É que teria que ver o contexto da situação ali, se ele tem uma } \\
\text { condição de emergência reversível, o que há de ser tratado naquele momento (...)." }\end{array}$ \\
\hline & & $\begin{array}{l}\text { M7: “(...) Mas sempre uma coisa que me incomoda é essa dúvida, o quanto aquilo que } \\
\text { está escrito lá é o que está acontecendo na prática com o paciente na tua frente, e às } \\
\text { vezes você pode deixar de fazer alguma coisa que deveria ter feito. É um dilema ético } \\
\text { que não tem solução.” }\end{array}$ \\
\hline & \multirow{5}{*}{$\begin{array}{c}\text { Incerteza sobre } \\
\text { a validade das } \\
\text { DAV } \\
\text { considerando } \\
\text { valores e } \\
\text { motivações do } \\
\text { paciente ao } \\
\text { escrever o } \\
\text { documento }\end{array}$} & $\begin{array}{l}\text { M1: "Isso faz pensar que esta pessoa tem alguma coisa no passado dela que motivou a } \\
\text { fazer isso, eu gostaria de saber o que que é." }\end{array}$ \\
\hline & & $\begin{array}{l}\text { M5: "(...) eu acho que depende de quem é esse paciente, de que funcionalidade ele tem, } \\
\text { de qual é a história dele de saúde, história de vida antes daquele momento de } \\
\text { emergência." }\end{array}$ \\
\hline & & $\begin{array}{l}\text { M6: "(...) talvez até na mente dele não esteja esclarecido ou até esteja enviesado por } \\
\text { questões que ele vivenciou, da experiência dele de vida, de pessoas que faleceram do } \\
\text { coração ou que tiveram sequelas de intervenções e que ele presenciou e conviveu com } \\
\text { essas situações, e isso impactou talvez negativamente nele, na experiência dele, } \\
\text { mudando a visão que ele tem inclusive no benefício de determinados recursos que ele } \\
\text { poderia fazer uso, e ser beneficiado." }\end{array}$ \\
\hline & & $\begin{array}{l}\text { M7: “(...) talvez na época [1994] a percepção que se tivesse desse tipo de intervenção } \\
\text { fosse outra.” }\end{array}$ \\
\hline & & $\begin{array}{l}\text { M8: "Ele assinou em 94, a gente tá em qual ano, agora? 2019?"; "É que eu acho que as } \\
\text { pessoas ao longo da vida elas podem mudar de ideia. Então, às vezes...me faz pensar que } \\
\text { talvez, ao longo do tempo, ele tivesse mudado de ideia, tivesse mudado de percepção } \\
\text { (...)." }\end{array}$ \\
\hline & \multirow{2}{*}{$\begin{array}{l}\text { Pouco } \\
\text { conhecimento } \\
\text { prévio a respeito } \\
\text { das DAV } \\
\text { levando ao } \\
\text { desconforto do } \\
\text { médico } \\
\end{array}$} & $\begin{array}{l}\text { M1: "Eu não me sinto à vontade com isso, porque não é um documento comum de você } \\
\text { ver no dia-a-dia, aliás, é um documento extremamente incomum, em } 28 \text { anos de } \\
\text { profissão e eu nunca tinha visto um documento desse, essa é a primeira vez que eu vejo } \\
\text { (...)." }\end{array}$ \\
\hline & & $\begin{array}{l}\text { M2: “(...) não é o habitual a gente ver esse tipo de coisa, então às vezes a gente até não } \\
\text { está acostumado, pode ser até que assuste um pouco, ou que você se sinta um pouco } \\
\text { encabulado em relação a isso(...)." }\end{array}$ \\
\hline \multirow[t]{5}{*}{$\begin{array}{l}\text { Reconhecimento } \\
\text { das DAV como } \\
\text { instrumentos de } \\
\text { exercício de } \\
\text { autonomia do } \\
\text { paciente }\end{array}$} & $\begin{array}{l}\text { Autonomia } \\
\text { como princípio } \\
\text { prima facie }\end{array}$ & $\begin{array}{l}\text { M8: "Se ele entrasse em insuficiência respiratória, eu não intubaria e, que mais que ele } \\
\text { fala aqui [lendo a diretiva] 'prolongado através de aparelhos', e não intubaria, mas essa } \\
\text { questão aqui, 'quero partir consciente' talvez não faria alguma coisa aí pra fazer uma } \\
\text { sedação pra ele, sabe, não sei, entenderia assim. Como ele fala 'quero partir consciente } \\
\text { para o outro lado da vida', eu acho que fazer alguma coisa pra rebaixar o nível de } \\
\text { consciência, provocar isso, talvez eu não faria, mas não intubaria também." }\end{array}$ \\
\hline & \multirow[t]{4}{*}{$\begin{array}{l}\text { Autonomia } \\
\text { compartilhada }\end{array}$} & $\begin{array}{l}\text { M2: “(...) acho que o mais importante foi a participação da família junto da decisão, } \\
\text { porque não acho que é uma decisão minha nem deles, é uma decisão em conjunto, você } \\
\text { não pode jogar essa reponsabilidade só para a família, você não pode decidir isso } \\
\text { sozinho." }\end{array}$ \\
\hline & & $\begin{array}{l}\text { M3: "(...) respeitaria totalmente a decisão dele e chamaria ele para participar do que } \\
\text { fosse instituído ali de plano diagnóstico e terapêutico." }\end{array}$ \\
\hline & & $\begin{array}{l}\text { M4: “(...) a minha primeira conduta seria respeitar a vontade dele, eu acho que eu ia } \\
\text { fazer medidas menos invasivas, se fosse cabível, sabe, evitar ao máximo de fazer o que } \\
\text { ele expressamente colocou tanto no papel quanto me verbalizou, então não intubaria, não } \\
\text { colocaria em ambiente de UTI, pelo menos em um primeiro momento, salvo se fosse } \\
\text { uma decisão compartilhada com ele e seguiria com cuidado conforme a vontade dele." }\end{array}$ \\
\hline & & $\begin{array}{l}\text { M7: “(...) uma certa tranquilidade de que o paciente não quer que sejam feitas medidas } \\
\text { de suporte avançado, com risco de se sobreviver ficar com sequelas maiores, então isso } \\
\text { de certa forma até facilita." }\end{array}$ \\
\hline
\end{tabular}

Fonte: Autores. 


\section{Discussão}

\section{DAV como elementos de conflito moral}

Observamos que a maioria dos participantes do estudo trouxeram em seu discurso as DAV como elementos causadores de conflito moral na tomada de decisão. Considerando a DAV apresentada e as decisões moralmente complexas que poderiam advir nesse processo, pôde-se compreender a visão dos participantes sobre a aceitação das DAV em um momento de decisão clínica. Dentre essas, a manifestação de uma postura paternalista trouxe à tona a conduta ultrapassada do médico que, por acreditar deter o conhecimento técnico, impõe a indicação médica na tomada de decisão, retomando a beneficência do juramento hipocrático sob a forma de um paternalismo forte - neste, o desejo do paciente é suplantado pela intervenção médica, por se acreditar que aquele traria dano irreparável ao paciente (Beauchamp \& Childress, 2011). Nesse sentido, o MUD estaria relacionado ao desconforto do médico ao confrontar o desejo do paciente com a indicação médica envolvida no momento do atendimento, entendendo que um dano poderia advir do respeito à decisão do paciente e, portanto, esta deveria ser invariavelmente revista e modificada. O participante M6 traz essa questão em seu discurso:

“(...) muitas famílias querem uma coisa e a gente como profissional talvez tenha uma visão mais apurada do que aquela coisa vai trazer (...) muitas vezes você também consegue trazer o paciente e a família pra aquela visão e vocêe acaba trazendo eles pro que é justo (...)” (M6)

Horn (2014) conduziu um estudo qualitativo sobre o papel das DAV junto a médicos na Inglaterra e França, buscando por diferenças culturais na percepção destes sobre as DAV. Os resultados revelaram que, apesar de ambos os países terem sancionado leis regulamentadoras para as DAV e sobre direito de recusa do paciente a procedimentos no mesmo ano (2005), médicos franceses tendiam a uma postura mais paternalística no processo de tomada de decisão, desconsiderando os desejos do paciente caso houvesse uma forte opinião a respeito da decisão médica, diferentemente da visão dos médicos ingleses entrevistados. $\mathrm{O}$ autor interpretou esse resultado sob um prisma cultural, considerando que a cultura Anglo-saxã tem por base o conceito de respeito à autonomia do indivíduo e, portanto, mais habituada à ideia de participação do indivíduo na tomada de decisão, enquanto a cultura francesa tende a dar prioridade aos valores sociais coletivos acima dos valores individuais. Considerando-se o Brasil também como uma cultura predominantemente Latina, assim como a França, nos leva a ponderar se influências culturais podem ser atribuídas a essa postura paternalista identificada em nosso estudo.

Em uma visão menos paternalista da questão, mas ainda levando em consideração princípios de autonomia e não maleficência, a fonte de conflito moral na tomada de decisão em situações de incerteza prognóstica também foi identificada no conteúdo das entrevistas dos participantes. Nesse caso, o conflito se daria entre o desejo de respeitar a autonomia do paciente e a possibilidade de ir contra o princípio de não-maleficência, omitindo uma intervenção que resultaria em um dano final ao paciente. O participante M7 traz essa percepção em seu discurso:

"Mas sempre uma coisa que me incomoda é essa dúvida, o quanto aquilo que está escrito lá é o que está acontecendo na prática com o paciente na tua frente, e às vezes você pode deixar de fazer alguma coisa que deveria ter feito. É um dilema ético que não tem solução." (M7)

Por outro lado, o procedimento, inicialmente proposto pelo médico como uma medida beneficente, poderia levar a desfechos negativos ou mesmo danos reais considerando o prognóstico incerto da doença. Estes dois desfechos possíveis revelam o desafio moral existente na tomada de decisão em situações de incerteza prognostica podendo o sofrimento advindo da dificuldade na tomada de decisão finalmente culminar em MUD. 
O desafio de acatar o conteúdo de uma DAV no contexto de incerteza prognóstica também esteve presente em outros estudos. Leder e colaboradores (2015), em estudo realizado na Alemanha, mostraram o questionamento das DAV de pacientes admitidos em UTI, entre outras razões, devido às incertezas prognósticas enfrentadas nesse contexto. A utilização das DAV pelos médicos participantes como guias sobre valores e desejos do paciente e não sua interpretação e execução literal foi um marco do estudo.

Sabemos que, ao construir a DAV, o indivíduo formula suas preferências baseado em valores e desejos, considerando sua qualidade de vida nas atuais condições de saúde e/ou numa situação futura potencial, como em doenças terminais (Pearlman, Starks, Cain, \& Cole, 2005). Portanto, o conteúdo da DAV é definido sobe uma base hipotética de futuro para o paciente e que nem sempre irá se traduzir na realidade da prática clínica. Por outro lado, todo indivíduo possui o direito de fazer parte do processo de deliberação das decisões que afetam sua vida, e para isso deve possuir informação adequada também sobre as circunstâncias não previstas, visto que a imprevisibilidade é inerente no cuidado assistencial (Nunes \& Anjos, 2014). De acordo com Nunes e Anjos (2014), uma medida que pode ser tomada diante desta trajetória seria rever o documento frequentemente com o paciente a cada intercorrência e ressaltar a possibilidade de modificação do mesmo sempre que necessário. A atualização do documento junto ao paciente, frente à novos fatos médicos, pode ser de fato uma ferramenta para atenuar as questões referentes à adequação dos desejos do paciente frente a situações de incerteza prognóstica. No entanto, mesmo reconhecidamente necessária, é uma prática ainda pouco realizada (Otte, Elger, Jung, \& Bally, 2016), algo que pudemos observar na própria DAV utilizada no estudo, cuja construção datava de mais de duas décadas.

No que tange à questão da visão do paciente do que é o bem para si, as motivações do paciente na construção de sua DAV também foram questionadas na sua aplicação para tomada de decisão. Nesse contexto, o MUD estaria relacionado ao questionamento quanto à influência de experiências prévias do paciente na construção dos desejos e valores expressos no documento. Essa percepção pode ser observada na fala do participante M6:

“(...) talvez até na mente dele não esteja esclarecido ou até esteja enviesado por questões que ele vivenciou, da experiência dele de vida, de pessoas que faleceram do coração ou que tiveram sequelas de intervenções e que ele presenciou e conviveu com essas situações, e isso impactou talvez negativamente nele, na experiência dele, mudando a visão que ele tem inclusive no benefício de determinados recursos que ele poderia fazer uso, e ser beneficiado." (M6)

De fato, a construção conjunta do documento nem sempre é possível junto a todos os médicos que assistem o paciente, e compreender a complexidade da biografia deste, assim como sua interferência nas motivações do paciente ao redigir sua DAV, demanda tempo de escuta por parte do profissional. Uma dificuldade que pode se apresentar nesse contexto se dá justamente no aspecto da comunicação, como foi evidenciado no estudo qualitativo de Cogo e colaboradores (2016), realizado no Rio Grande do Sul. Neste, médicos ressaltaram a importância de questões como tempo para se comunicar junto ao paciente e a família e de método adequado de apresentação das informações sobre os diagnósticos do paciente e as DAV.

Observamos também, na fala de participantes do estudo, o incômodo do profissional em relação às DAV por desconhecimento ou pouco contato prévio com o instrumento, estando MUD então associado ao desconforto por não ter conhecimento adequado ou suficiente sobre o documento. O participante M1 nos demonstra claramente essa questão:

“Eu não me sinto à vontade com isso, porque não é um documento comum de você ver no dia-a-dia, aliás, é um documento extremamente incomum, em 28 anos de profissão e eu nunca tinha visto um documento desse, essa é a primeira vez que eu vejo (...).” (M1) 
Chehuen e colaboradores (2015), em estudo realizado em Minas Gerais com profissionais de saúde (médicos e nãomédicos), evidenciou que apenas 37,89\% tinham conhecimento prévio sobre as DAV. Esse resultado foi similar ao de um estudo anterior, de 2011, realizado com profissionais médicos em Santa Catarina (Piccini, Steffani, Bonamigo, Bortoluzzi, \& Schlemper Jr, 2011). Considerando o pouco avanço do Brasil na questão das DAV comparativamente a países europeus e aos EUA, tais resultados não são surpreendentes. No entanto, mesmo em países onde as DAV já dispõem de uma regulamentação legal, a implementação do instrumento também encontra desafios semelhantes. Um estudo suíço qualitativo realizado em 2015 com médicos, sobre uso das DAV no contexto de cirurgia cardíaca eletiva, evidenciou que, embora os médicos considerassem o instrumento útil para exercício da autonomia do paciente, muitos apresentavam dificuldade em estimular ou participar da construção do documento. Dentre os motivos observados estavam o medo e a falta de conhecimento sobre as DAV (Gigon, Merlani, \& Ricou, 2015).

Portanto, o MUD vivenciado pelos participantes do estudo se relaciona, em graus diversos, com o paternalismo e a valorização do bem biomédico, ou seja, aquele relacionado puramente à indicação clínica, seguindo os moldes da beneficência hipocrática. O bem biomédico, nesse contexto, pode ainda perder clareza diante da incerteza inerente à medicina e seus prognósticos e, diante de uma eventual contraposição à autonomia do paciente, pode também traduzir dificuldade na tomada de decisão, sendo fonte de MUD. Nesse sentido, o processo de comunicação eficaz entre os atores da tomada de decisão é fundamental, a fim de reconhecer e incorporar as incertezas e valores morais envolvidos.

\section{Reconhecimento das DAV como instrumentos de exercício da autonomia do paciente}

Embora nosso estudo tenha evidenciado questões relacionadas ao MUD no conteúdo das entrevistas, o reconhecimento das DAV como instrumentos de exercício da autonomia do paciente também esteve presente na fala da maioria dos entrevistados. Considerando a expressão dos desejos do paciente como uma das funções das DAV, entende-se que esta percepção do profissional médico é inteiramente justificável e desejada. No entanto, o conceito de autonomia é amplo, e abarca em si dimensões que vão além do senso comum de liberdade de ação. A autonomia, ou respeito à autonomia, como princípio prima facie é um conceito que deriva da bioética principialista de Beauchamp e Childress (Beauchamp \& Childress, 2011). Embora seja um termo amplo em suas definições filosóficas, pressupõe-se que um indivíduo autônomo seja aquele capaz de agir livremente conforme suas decisões, incluindo, portanto, duas características principais: a liberdade frente a influências controladoras e a capacidade de agir de forma intencional (Beauchamp \& Childress, 2011). No entanto, para esses autores, ser autônomo não é sinônimo de ser um agente autônomo, visto que, para este, é necessário reconhecer o direito do indivíduo em expressar suas opiniões, realizar escolhas e agir conforme seus valores e crenças pessoais. A interpretação da DAV sob um prisma principialista pode ser exemplificada no discurso do participante M8, que traz uma visão mais literal de preservação dos desejos do paciente:

"Se ele entrasse em insuficiência respiratória, eu não intubaria e, que mais que ele fala aqui [lendo a diretiva] 'prolongado através de aparelhos', e não intubaria, mas essa questão aqui, 'quero partir consciente' talvez não faria alguma coisa aí pra fazer uma sedação pra ele, sabe, não sei, entenderia assim. Como ele fala 'quero partir consciente para o outro lado da vida', eu acho que fazer alguma coisa pra rebaixar o nivel de consciência, provocar isso, talvez eu não faria, mas não intubaria também." (M8)

Nas DAV, o testamento vital traduz o princípio de pura autonomia principialista, pois revela a manifestação expressa de vontade do indivíduo capaz em fazê-lo (Dadalto, 2013; Dadalto et al., 2013). No entanto, nem sempre os valores do paciente e suas escolhas convergem com os do médico e, considerando os conflitos morais que possam advir nesse processo, a 
busca por uma decisão compartilhada pode ser grande valia nesse contexto a fim de se obter o melhor curso de ação, como foi identificado no segundo núcleo de sentido desta categoria. O conceito de autonomia compartilhada, defendido por Bergsma e Thomasma (2000), firma-se na condição mútua que existe entre a doença e a busca pela cura para paciente e médico. Dessa forma, quando as decisões são discutidas a fim de serem devidamente negociadas entre ambos, a divisão de responsabilidades também é compartilhada (Bergsma \& Thomasma, 2000). O participante M2 coloca esse conceito implícito em seu discurso:

“(...)acho que o mais importante foi a participação da família junto da decisão, porque não acho que é uma decisão minha nem deles, é uma decisão em conjunto, você não pode jogar essa reponsabilidade só para a família, você não pode decidir isso sozinho." (M2)

A decisão compartilhada busca a ponderação entre o médico que obedece de forma absoluta as vontades do paciente e aquele que impõe sua noção de bem paternalista. Na visão moderna desse modelo, o profissional médico expõe as questões médicas e as possibilidades de intervenção - ou seja, bem biomédico - enquanto o paciente expressa seus valores, e ambos se unem na tomada de decisão pelo curso de ação a ser seguido. Entretanto, a implementação de um real modelo de decisão compartilhada também enfrenta desafios, principalmente ao se desvencilhar de modelo apenas voltado para o consentimento informado. A crença de que ao profissional médico cabe informar os fatos de forma acurada imparcialmente, e ao paciente, interpretar os tais fatos de acordo com seus próprios valores, desconsidera aspectos importantes: a relevância dos valores do profissional no planejamento do cuidado, e que dificilmente o médico conseguirá expor os fatos de forma imparcial a ponto de não ser influenciado por aqueles (Beers, Lee Nilsen, \& Johnson, 2017; Tonelli \& Sullivan, 2019). Dessa forma, a tomada de decisão pelo paciente, na forma de uma autonomia isolada, apenas a partir das informações fornecidas pelo profissional médico, não configura decisão compartilhada e sim um modelo informativo de tomada de decisão, diametralmente oposta ao modelo paternalista (Tonelli \& Sullivan, 2019). Da mesma forma, a decisão compartilhada requer uma execução que inclua verdadeiramente paciente-família e médico, a fim de que ambos acordem sobre a decisão final, considerando que o médico trará os fatos agregando neles seus valores e percepções, e a tomada de decisão por parte do paciente também estará influenciada pelos diversos fatores relacionados à compreensão da doença (Beers et al., 2017).

Nesse contexto, a decisão compartilhada também apresenta outros desafios. Há necessidade de consenso entre as partes envolvidas na tomada de decisão, assim como não há imediatismo: dificilmente uma decisão compartilhada consegue ser atingida em um encontro pontual, pois requer uma relação médico-paciente-família aprofundada, sendo, portanto, de difícil realização em cenário de emergências (Tonelli \& Sullivan, 2019). Se a decisão compartilhada envolve o reconhecimento dos valores e princípios de todos os agentes da decisão, o processo de comunicação adequado entre médico e paciente-família também é fundamental para o sucesso. Da mesma forma que a discordância entre partes pode ser um convite à uma análise mais profunda do real conhecimento e entendimento do problema por parte do paciente-família, assim como dos valores envolvidos entre todos os agentes da decisão. Quando realizada nesses moldes, a discordância definitiva é rara, mas, se ainda presente, pode determinar a dissolução da relação médico-paciente (Tonelli \& Sullivan, 2019).

Portanto, o respeito à autonomia do paciente, seus valores e crenças, é um importante princípio ético, moralmente desejável, e um alvo a ser perseguido ao longo da relação médico-paciente. Nesse sentido, a decisão compartilhada é uma estratégia que divide responsabilidades entre médico e paciente-família, assim como auxilia na compreensão dos valores envolvidos entre todos os agentes da decisão. Promove o respeito à autonomia do paciente - ao reconhecer seus valores e não valorizar apenas o bem biomédico envolvido - e considera, nesse contexto, o que é trazido como beneficente pelo profissional médico, não permitindo que o indivíduo fique isolado em sua autonomia, esta indubitavelmente influenciada pelo contexto de doença. Uma DAV construída e continuamente revisada sob os moldes da decisão compartilhada poderia, portanto, auxiliar a 
mitigar o potencial MUD envolvido na tomada de decisão.

\section{Considerações Finais}

O MUD, embora seja um conceito ainda não unânime na literatura, ganha força quando consideramos os inúmeros conflitos morais presentes na prática clínica e os efeitos psicológicos negativos que estes podem exercer sobre o profissional de saúde, incluindo o profissional médico. Embora o intuito primário das DAV seja auxiliar o profissional médico a compreender os valores do paciente, conflitos morais podem surgir quando o profissional encara situações em que precisa decidir sobre acatar ou não o que se encontra expresso no documento, principalmente quando a autonomia do paciente entra em conflito com outros princípios como a beneficência e não-maleficência. Em nosso estudo, embora as DAV tenham sido percebidas como instrumentos de exercício da autonomia, a presença de diversos elementos levando a conflitos morais por parte dos profissionais entrevistados também foi relevante. Em última análise, estes desafios morais podem levar ao MUD do profissional médico, o que pode repercutir de forma negativa durante o processo de tomada de decisão, implicando inclusive no desrespeito à autonomia do paciente. Para que a autonomia do paciente seja de fato respeitada, o primeiro passo é a destituição do modelo paternalista como ferramenta para tomada de decisão. Assim, uma possível forma de evitar o MUD seria o estímulo à decisão compartilhada entre o médico, seu paciente e familiares, o que requer que os profissionais médicos sejam educados e instrumentalizados para o reconhecimento dos valores morais de todos os envolvidos na tomada de decisão. Embora apresente alguns desafios na sua aplicação, por meio da decisão compartilhada é possível a busca pelo equilíbrio entre melhores interesses de médico e paciente-família, não priorizando apenas o bem biomédico envolvido, mas os valores e princípios de todos os agentes dessa decisão.

O presente estudo também apresenta limitações. Primeiramente, a DAV utilizada é datada de 1994, o que pode ter influenciado na sua interpretação pelos participantes do estudo. Entretanto, por não haver modelo padrão de DAV no Brasil até o momento, e pelo próprio paciente ter apresentado a mesma diretiva em 2018, sem modificações, a veracidade de seu conteúdo justificou sua utilização neste estudo. Quanto ao desenho do estudo, por ter sido realizado em um único hospital no sul do Brasil, junto a uma amostra limitada de participantes, não podemos extrapolar os resultados encontrados como sendo o pensamento do profissional médico brasileiro. No entanto, compreendendo que a pesquisa qualitativa tem por finalidade explorar o fenômeno, este estudo pode servir como um olhar inicial sobre o assunto do MUD relacionado às DAV no profissional médico, algo ainda pouco discutido na literatura, permitindo que o assunto seja abordado no futuro sob outros olhares e métodos.

Compreender como o MUD se manifesta no profissional médico frente às DAV nos permite traçar estratégias futuras para estudos que identifiquem os fatores relacionados ao MUD, não somente no médico como também nos demais profissionais de saúde, assim como a elaboração de instrumentos de avaliação que considerem o conceito ampliado de distresse moral e a proposição de estratégias para mitigar o MUD.

\section{Referências}

Bardin, L. (2011). Análise de Conteúdo. Edições 70.

Barlem, E. L. D., Lunardi, V. L., Lunardi, G. L., Dalmolin, G. de L., \& Tomaschewski, J. G. (2012). Vivência do sofrimento moral na enfermagem: percepção da enfermeira. Revista Da Escola de Enfermagem Da USP, 46(3), 681-688. https://doi.org/10.1590/S0080-62342012000300021

Beauchamp, T. L., \& Childress, J. F. (2011). Princípios de Ética Biomédica (2a ed.). Edições Loyola.

Beers, E., Nilsen, M. L., \& Johnson, J. T. (2017). The Role of Patients: Shared Decision-Making. Otolaryngologic Clinics of North America, 50(4), 689-708. https://doi.org/10.1016/j.otc.2017.03.006

Bergsma, J., \& Thomasma, D. C. (2000). Autonomy and Ethical Modes of the Doctor-Patient Relationship. In Autonomy and Clinical Medicine. International Library of Ethics, Law, and the New Medicine (2nd ed.). Springer. https://doi.org/10.1007/978-94-017-0821-0_7 
Bernardi, C. M. S., Villagran, C. A., Lanes, T. C., Schutz, T. C., \& Dalmolin, G. de L. (2020). Tendências de teses e dissertações brasileiras acerca do sofrimento moral na enfermagem. Research, Society and Development, 9(10), e5239108950. https://doi.org/10.33448/rsd-v9i10.8950

Bussinguer, E. C. de A., \& Barcellos, I. A. (2013). O direito de viver a própria morte e sua constitucionalidade. Ciência \& Saúde Coletiva, 18(9), 2691-2698. https://doi.org/10.1590/S1413-81232013000900024

Campbell, S. M., Ulrich, C. M., \& Grady, C. (2016). A Broader Understanding of Moral Distress. The American Journal of Bioethics, 16(12), 2-9. https://doi.org/10.1080/15265161.2016.1239782

Chehuen Neto, J. A., Ferreira, R. E., Silva, N. C. S. Da, Delgado, Á. H. D. A., Tabet, C. G., Almeida, G. G., ... Vieira, I. F. (2015). Testamento vital: o que pensam profissionais de saúde? Revista Bioética, 23(3), 572-582. https://doi.org/10.1590/1983-80422015233094

Cogo, S. B., Lunardi, V. L., Quintana, A. M., Girardon-Perlini, N. M. O., \& Silveira, R. S. da. (2016). Desafios da implementação das diretivas antecipadas de vontade à prática hospitalar. Revista Brasileira de Enfermagem, 69(6), 1031-1038. https://doi.org/10.1590/0034-7167-2016-0085

Conselho Federal de Medicina. Resolução CFM no 1.995/2012. DOU.2012;(I):269-270.

Corradi-Perini, C., Beltrão, J. R., \& Ribeiro, U. R. V. de C. O. (2020). Circumstances Related to Moral Distress in Palliative Care: An Integrative Review. American Journal of Hospice and Palliative Medicine ${ }^{\circledR}, 104990912097882$. https://doi.org/10.1177/1049909120978826

Corley, M. C., Elswick, R. K., Gorman, M., \& Clor, T. (2001). Development and evaluation of a moral distress scale. Journal of Advanced Nursing, 33(2), 250-256. https://doi.org/10.1046/j.1365-2648.2001.01658.x

Dadalto, L. (2013). Distorções acerca do testamento vital no Brasil (ou o porquê é necessário falar sobre uma declaração prévia de vontade do paciente terminal). Revista de Bioética y Derecho, (28), 61-71. https://doi.org/10.4321/S1886-58872013000200006

Dadalto, L., Tupinambás, U., \& Greco, D. B. (2013). Diretivas antecipadas de vontade: um modelo brasileiro. Rev. Bioét. (Impr.), 21(3), 463-476. https://doi.org/10.1590/S1983-80422013000300011

Fourie, C. (2015). Moral Distress and Moral Conflict in Clinical Ethics. Bioethics, 29(2), 91-97. https://doi.org/10.1111/bioe.12064

Fourie, C. (2018). Who Is Experiencing What Kind of Moral Distress? Distinctions for Moving from a Narrow to a Broad Definition of Moral Distress. AMA Journal of Ethics, 20(8), E787-792. https://doi.org/10.1001/amajethics.2018.787

Gigon, F., Merlani, P., \& Ricou, B. (2015). Swiss physicians' perspectives on advance directives in elective cardiovascular surgery. Minerva Anestesiologica, 81(10), 1061-1069.

Greco, P. B. T., Bernardi, C. M. S., Balbueno, B. L., Machado, L. M., Magnago, T. S. B. de S., \& Dalmolin, G. de L. (2020). Sofrimento moral em trabalhadores de Enfermagem de um hospital filantrópico. Research, Society and Development, 9(8), e111985391. https://doi.org/10.33448/rsd-v9i8.5391

Hamric, A. B., Borchers, C. T., \& Epstein, E. G. (2012). Development and Testing of an Instrument to Measure Moral Distress in Healthcare Professionals. AJOB Primary Research, 3(2), 1-9. https://doi.org/10.1080/21507716.2011.652337

Horn, R. (2014). "I don't need my patients" opinion to withdraw treatment": Patient preferences at the end-of-life and physician attitudes towards advance directives in England and France." Medicine, Health Care and Philosophy, 17(3), 425-435. https://doi.org/10.1007/s11019-014-9558-9

Jameton, A. (2013). A Reflection on Moral Distress in Nursing Together With a Current Application of the Concept. Journal of Bioethical Inquiry, 10(3), 297-308. https://doi.org/10.1007/s11673-013-9466-3

Jameton, A. (2017). What Moral Distress in Nursing History Could Suggest about the Future of Health Care. AMA Journal of Ethics, 19(6), 617-628. https://doi.org/10.1001/journalofethics.2017.19.6.mhst1-1706

Lamiani, G., Setti, I., Barlascini, L., Vegni, E., \& Argentero, P. (2017). Measuring Moral Distress Among Critical Care Clinicians. Critical Care Medicine, 45(3), 430-437. https://doi.org/10.1097/CCM.0000000000002187

Leder, N., Schwarzkopf, D., Reinhart, K., Witte, O. W., Pfeifer, R., \& Hartog, C. S. (2015). The Validity of Advance Directives in Acute Situations. Deutsches Aerzteblatt Online. https://doi.org/10.3238/arztebl.2015.0723

Levi, B. H., \& Green, M. J. (2010). Too Soon to Give Up: Re-examining the Value of Advance Directives. The American Journal of Bioethics, 10(4), 3-22. https://doi.org/10.1080/15265161003599691

McCarthy, J., \& Deady, R. (2008). Moral Distress Reconsidered. Nursing Ethics, 15(2), 254-262. https://doi.org/10.1177/0969733007086023

Morley, G., Bradbury-Jones, C., \& Ives, J. (2020). What is 'moral distress' in nursing? A feminist empirical bioethics study. Nursing Ethics, 27(5), 12971314. https://doi.org/10.1177/0969733019874492

Nunes, M. I., \& Anjos, M. F. dos. (2014). Diretivas antecipadas de vontade: benefícios, obstáculos e limites. Revista Bioética, 22(2), 241-251. https://doi.org/10.1590/1983-80422014222005

Otte, I. C., Elger, B., Jung, C., \& Bally, K. W. (2016). The utility of standardized advance directives: the general practitioners' perspective. Medicine, Health Care and Philosophy, 19(2), 199-206. https://doi.org/10.1007/s11019-016-9688-3

Pearlman, R. A., Starks, H., Cain, K. C., \& Cole, W. G. (2005). Improvements in Advance Care Planning in the Veterans Affairs System. Archives of Internal Medicine, 165(6), 667. https://doi.org/10.1001/archinte.165.6.667 
Research, Society and Development, v. 10, n. 14, e575101422290, 2021

(CC BY 4.0) | ISSN 2525-3409 | DOI: http://dx.doi.org/10.33448/rsd-v10i14.22290

Piccini, C. F., Steffani, J. A., Bonamigo, É. L., Bortoluzzi, M. C., \& Schlemper Jr, B. R. (2011). Testamento Vital na perspectiva de médicos, advogados e estudantes a Living Will in the perspective of doctors, lawyers and students El Testamento Vital en la perspectiva de doctores, de abogados y de estudiantes. Revista -Centro Universitário São Camilo, 5(4), 384-391. http://www.saocamilo-sp.br/pdf/bioethikos/89/A4.pdf

Ramos, A. M., Barlem, E. L. D., Barlem, J. G. T., Rocha, L. P., Dalmolin, G. de L., \& Figueira, A. B. (2017). Cross-cultural adaptation and validation of the Moral Distress Scale-Revised for nurses. Revista Brasileira de Enfermagem, 70(5), 1011-1017. https://doi.org/10.1590/0034-7167-2016-0518

Rietjens, J. A. C., Sudore, R. L., Connolly, M., van Delden, J. J., Drickamer, M. A., Droger, M., \& Korfage, I. J. (2017). Definition and recommendations for advance care planning: an international consensus supported by the European Association for Palliative Care. The Lancet Oncology, 18(9), e543-e551. https://doi.org/10.1016/S1470-2045(17)30582-X

Savel, R. H., \& Munro, C. L. (2015). Moral Distress, Moral Courage. American Journal of Critical Care, 24(4), 276-278. https://doi.org/10.4037/ajcc2015738

Tonelli, M. R., \& Sullivan, M. D. (2019). Person-centred shared decision making. Journal of Evaluation in Clinical Practice, 25(6), 1057-1062. https://doi.org/10.1111/jep. 13260

Tong, A., Sainsbury, P., \& Craig, J. (2007). Consolidated criteria for reporting qualitative research (COREQ): a 32 -item checklist for interviews and focus groups. International Journal for Quality in Health Care, 19(6), 349-357. https://doi.org/10.1093/intqhe/mzm042 